\title{
Degenerative Disc Pathology in Patients with Ankylosing Spondylitis: Its Frequency and Relation with Disease Activity \\ A Atilabey ${ }^{1}$, M A Çebiçci ${ }^{1}$, Ö Karabiyik ${ }^{2}$, S T Sütbeyaz ${ }^{1}$, Ş Hocaoğlu ${ }^{1}$, A Koc ${ }^{1}$, Ü E Vurdem $^{2}$
}

\begin{abstract}
Objective: To determine the frequency of degenerative disc pathology in patients with ankylosing spondylitis (AS) and explore its association with parameters of disease activity.

Material-Method: Patients between 15 and 65 years of age diagnosed with AS whose lumbar magnetic resonance imaging records were available in registry database were enrolled. A total of 88 patients and 440 discs were evaluated. Modic classification was used for endplate degeneration and Pfirrmann scale and the degree of disc herniation were analyzed for disc degeneration. Aforementioned parameters were evaluated to determine whether they were associated with erythrocyte sedimentation rate (ESR), serum C- reactive protein (CRP) and Bath Ankylosing Spondylitis Disease Activity Index (BASDAI). Values were expressed as frequencies and percentages for categorical variables. Spearman's test was used for correlation analysis.
\end{abstract}

Results: Among 440 discs examined, Modic changes were detected in 13\% (Person count (PC): 30.7\%) and Modic type 2 changes were the most common (Disc Count (DC): 8.9\%, PC: \% 25). The most frequent Pfirrmann change was grade 1 degeneration (DC: $57.7 \%, 254$ disc) and the most common form of disc herniation was bulgingdir (DC: $21.7 \%$, PC: 67\%). A positive correlation was found between L1-L2 disc herniation and BASDAI activity and between L2-L3 disc herniation and CRP level $(\mathrm{p}<0.05)$. Conclusion: A high prevalence of Modic type 2 changes and bulging herniation was found. While this study may provide some insight for degenerative disc disease in AS, further studies involving a larger number of patients and a control group are needed.

Keywords: Ankylosing spondylitis, disc degeneration, disc herniation, modic changes. 
From: ${ }^{1}$ Department of Physical Therapy and Rehabilitation, ${ }^{2}$ Department of Radiology Clinic, Kayseri Training and Research Hospital, Kayseri, Turkey

\section{Correspondence:}

A Ayse, Department of Physical Therapy and Rehabilitation, Kayseri Training and Research Hospital, 38010, Kayseri, Turkey. Fax: +90 352 3205510; e-mail : ayseatilabey@ gmail.com.

\section{INTRODUCTION}

Ankylosing spondylitis (AS) is a member and also a prototype of the spondyloarthropathy (SPA) family of inflammatory disorders (1). The most common involvement is the involvement of axial skeleton (2). Main clinical symptom is low back pain associated with sacroiliac joint and spinal involvement (3). In AS, disease-specific vertebral changes include Romanus lesion, squaring of the vertebral bodies, syndesmophyte, "bamboo spine" appearance, ankylosis and Andersson lesions. In addition to these changes, disc degeneration and damage and destruction of vertebral endplates occur in patients with AS. Such changes resemble those seen in severe degenerative disc disease (4, 5). Intervertebral disc degeneration is thought to be the first step in degenerative spinal changes. Furthermore, disc degeneration is considered to be one of the causes of several symptoms (neck pain or low back pain) (6).

Disc involvement plays a crucial role in the degenerative process that occurs in axial spine. In AS, intervertebral disc involvement has been overshadowed by disease-specific pathologies and in the present study, disc involvement in AS will be examined extensively. Usually, Andersson lesion causing discovertebral erosion has been the primary focus of studies in AS patients (7-13). There are few studies that explored the incidence of degenerative disc disease in AS and these studies investigated solely endplate degeneration 
(14-15). In a separate study that examined SPA group of diseases as a whole, both endplate degeneration and disc degeneration were evaluated (16). However, as a result of our literature search, we did not identify any studies which investigated endplate degeneration, disc degeneration and disc herniation collectively in AS patients.

The purpose of the current study was to determine the frequency of degenerative disc pathology in AS patients and explore its association with parameters of disease activity.

\section{MATERIAL AND METHOD}

The study was conducted retrospectively by examining patient registry database. Before initiation of the study, approval was obtained from Education Planning Committee and Ethics Committee of Kayseri Research and Training Hospital. Patients between 15 and 65 years of age were enrolled. Study patients were selected from outpatients with examinations performed in Kayseri Research and Training Hospital from December 2013 to January 2015. Patients diagnosed with AS according to the 1984 modified New York classification criteria and/or 2009 ASAS axial spondyloarthropathy classification criteria were studied $(17,18)$. Among those patients, patients with lumbar spine MRI records were included in the study.

Patients with other forms of spondyloarthropathy as well as AS, past history of a surgical operation to lumbar region, metallic implants that could impair image quality, a previous trauma or fracture to lumbar region, spondylitis due to infectious diseases or a metabolic bone disease affecting degenerative process were excluded from the study. A flowchart diagram is provided in Table

\section{MRI Evaluation}

Lumbar MRI scans of patients were examined by three radiologists with an expertise in musculoskeletal system. A total of 440 discs including L1-2, L2-3, L3-4, L4-5 and L5-S1 
levels were examined at axial and sagittal T1 and T2 sequences. All images were evaluated using 21-inch high-resolution screens. For lumbar MRI scans, Modic classification was used for endplate degeneration and Pfirrmann scale and the degree of disc herniation were analyzed for disc degeneration.

\section{Modic Changes}

A formal classification was first provided by Modic et al. in 1988 (19). Type 1 changes were hypointense on T1-weighted imaging (T1WI) and hyperintense on T2-weighted imaging (T2WI) and were shown to represent bone marrow edema and inflammation (Figure 1). Type 2 changes were hyperintense on T1WI and isointense or slightly hyperintense on T2WI and were associated with conversion of normal red hematopoietic bone marrow into yellow fatty marrow as a result of marrow ischemia. Modic type 3 changes were subsequently described as hypointense on both T1WI and T2WI and were thought to represent subchondral bone sclerosis. Mixed-type 1/2 and 2/3 Modic changes have also been reported, suggesting that these changes can convert from one type to another and that they all represent different stages of the same pathologic process. The absence of Modic changes, a normal anatomic appearance, has often been designated as Modic type 0 (20). In the present study, edema caused by a Romanus lesion or a Schmorl nodule was not included in the Modic classification.

\section{Degree of Disc Herniation}

The herniated disc was subdivided into bulging, subligamentous herniation and extrusion. Bulging was defined as displacement of the disc material greater than $50 \%$ of the disc 
circumference. When disc displacement was less than $50 \%$ of the disc circumference, the herniation was regarded as either protrusion (subligamentous herniation), or extrusion. The disc was defined as protrusion if the greatest distance between the edges of the disc material beyond the disc place was less than the distance between the edges of the base in any of the same planes. The extrusion was characterized as a greater diameter of the extruded fragment than of its base in any one plane (21).

\section{Pfirrmann grading system}

The degree of disc degeneration was graded on T2-weighted images with a modified Pfirrmann (22) scale as grade 1 (normal shape, no horizontal bands, distinction of nucleus, and anulus is clear), grade 2 (nonhomogeneous shape with horizontal bands, some blurring between nucleus and anulus), grade 3 (nonhomogeneous shape with blurring between nucleus and anulus, anulus shape still recognizable), grade 4 (nonhomogeneous shape with hypointensity, anulus shape not intact and distinction between nucleus and anulus impossible, disc height usually decreased) (Figure 2) and grade 5 (same as grade 4 but collapsed disc space).

\section{Laboratory parameters and disease activity}

In order to assess the relationship between disc pathologies observed in lumbar MRI scans and laboratory parameters of patients, average erythrocyte sedimentation rate (ESR) and Creactive protein (CRP) values obtained in the previous year were analyzed. To explore the association between disease activity and disc degeneration, patients were contacted via phone calls and Bath Ankylosing Spondylitis Disease Activity Index (BASDAI) questionnaire was administered to patients during the calls. 


\section{Analysis of the prevalence of abnormal findings}

The prevalence of the various abnormalities was calculated by disc count (DC) and person count (PC). DC is the number of discs irrespective of the subjects (0-440) and PC is the number of subjects with disc degeneration (0-88).

\section{Statistical Analysis}

Histogram and q-q plots were examined and Shapiro-Wilk's test was performed to assess data normality. Values were expressed as frequencies and percentages for categorical variables, and mean and standard deviation or median and minimum-maximum statistics for continuous variables. Spearman's test was used for correlation analysis. Analysis was conducted using R 3.1.1 (www.r-project.org) software. A p value less than 0.05 was considered statistically significant.

\section{RESULTS}

Of 88 patients enrolled in the study, $38(43.2 \%)$ were females and $50(56.8 \%)$ were males. The mean (+/-SD) age of study patients was 40.34+/-9.67 years. Clinical and demographic characteristics of patients are shown in Table 2. Table 3 summarizes the prevalance of Modic changes, disc bulging, protrusion, extrusion and disc degeneration levels in the MR studies. Table 4 shows the association of degenerative disc findings with ESR, CRP and BASDAI score

\section{Modic changes}


Among 440 discs examined, Modic changes were detected in 13\% (PC: 30.7\%) but absent in 87\% (PC: $64.7 \%$ ). Modic type 1 change was observed in $13.6 \%$ of patients (DC: $3.6 \%$ ). Modic type 2 was the most common pathologic Modic type affecting $25 \%$ of patients (DC: $8.9 \%$ ). Both Modic type 1 and type 2 changes were observed in $5.7 \%$ of patients (DC: 1.13\%), whereas Modic type 3 change was present in only 2 out of 440 discs. Modic changes were most commonly detected at L5-S1 disc (DC: $26.1 \%, 23$ discs) with decreasing frequency towards proximal. There was a significant association between Modic changes in L1-L2 and L3-L4 with CRP elevation $(\mathrm{p}<0.05)$. Also, a significant relation was observed between Modic changes in L1-L2 disc and BASDAI $(\mathrm{p}<0.05)$.

\section{Pfirrmann Classification}

The most common Pfirrmann change was grade 1 degeneration (DC: \%57.7, 254 discs), followed by grades 2-3 and 4. None of the patients had grade 5 disc degeneration. Grades 2, 3 and 4 Pfirrmann changes were most frequently detected in L4-L5 and L5-S1 discs with decreasing frequency towards proximal. Pfirrmann grade 4 disc degeneration was greater at L1-L2 and L5-S1 levels compared to other disc levels. L5-S1 disc degeneration showed a significant association with CRP $(\mathrm{p}<0.05)$. At other disc levels, Pfirrmann scale did not show any association with ESR, CRP and BASDAI.

\section{Disc Herniation}

Disc herniation was present in 137 discs out of 440 discs studied (DC: $31.13 \%$, PC: 85.2\%). Bulging was the most common form of disc herniation (DC: $21.7 \%$, PC: $67 \%$ ). Only 1 patient had disc extrusion and sequestered disc was not found in any patient. Disc herniation mostly affected L4-L5 and L5-S1 discs with decreasing frequency towards proximal. A 
positive correlation was found between L1-L2 disc herniation and BASDAI and between L2L3 disc herniation and CRP $(\mathrm{p}<0.05)$.

\section{DISCUSSION}

\section{Modic changes}

Substantial vertebral pathologies occur in the early and later stages of the disease in AS. This manifests itself clinically as low back pain. We think that degenerative disc disease affects AS patients to a great extent and has significance in contributing to low back pain in these patients.

There are several studies in literature that investigated Modic changes in asymptomatic subjects, general population and patients with degenerative disc disease. A review of these studies revealed that Weishaupt et al. found Modic type 1 changes in $2 \%$ of asymptomatic subjects, Modic type 2 in $7 \%$ and all types of Modic changes in $11 \%$ (23). In a separate study conducted with an asymptomatic population, Modic type 1 changes were found in $1.35 \%$ of the discs and Modic type 2 changes in $6.4 \%$ (24). A study on general population showed that Modic changes were present in $6 \%$ of individuals 40 years of age and $9 \%$ of individuals 44 years of age (25).

Modic changes were studied more extensively in patients with degenerative disc disease or low back pain in comparison to asymptomatic patients. Modic et al. studied patients with degenerative disc disease and found that Modic type 1 and 2 changes were present in $4 \%$ and $16 \%$ of patients, respectively (19). In a degenerative disc disease study by Toyone et al., the authors suggested that Modic type 1 changes could coexist with low back pain, whereas Modic type 2 changes could concurrently occur with stable degenerative disc disease (26). Kuisma et al. showed Modic type 2 changes in $21 \%$ of discs in degenerative 
disc disease and found that Modic changes are a common phenomenon in degenerative disc disease (27). Kjaer et al. reported a greater incidence of low back pain in a group of patients with both lumbar degenerative disc disease and Modic changes in comparison to the patient group with only degenerative disc disease without any Modic changes (28). This suggests that Modic changes might have a role in the development of low back pain. Although Jarvik et al. did not identify an association between low back pain and Modic changes (29), other studies suggested that Modic changes might actually be associated with low back pain (27, 30-32). Additionally, in a review of 33 studies involving patients with low back pain, Modic type 2 changes were most commonly detected and a positive correlation between Modic changes and low back pain was demonstrated (33).

Only few studies are available which explored Modic changes in AS. In a 2009 study conducted by Nguyen et al. that examined endplate degeneration in AS patients, 40 patients with a diagnosis of AS were evaluated for Modic changes. In that study, 15 out of 40 patients were found to have Modic 1 changes (PC: 37\%). However, the same study focused specifically on Modic type 1 changes rather than examining other Modic changes individually (14). In the current study, all types of Modic changes (1, 2 and 3) were studied separately and overall Modic changes were observed in $30.7 \%$ of patients. Of these changes, Modic type 1 changes were found in $13.6 \%$ (DC: $3.6 \%, 16$ discs) and Modic type 2 in 25\% (DC: $8.9 \%, 39$ discs) of study patients.

Similar to other study populations, Modic changes were most commonly observed in L4-5 and L5-S1 discs in the present study $(27,34,35,36)$.

In our study, the observed prevalence of Modic changes was greater in comparison to the prevalence in studies with asymptomatic patients or general population and similar to studies in patients with low back pain. Previous studies have shown a positive correlation between Modic changes and low back pain. We believe that the high prevelance of Modic changes 
that we observed in the present study might have significance in contributing to low back pain encountered in AS.

A significant association was found in the present study between Modic changes in L1-L2 and L3-L4 discs with elevated CRP $(\mathrm{p}<0.05)$. Also, there was a significant association between Modic changes in L1-L2 disc with BASDAI ( $\mathrm{p}<0.05)$. This finding led us to think that Modic changes in upper lumbar levels might be correlated with parameters of disease activity. Thus, studies involving thoracic and thoracolumbar regions might be of value to assess the association of Modic changes with disease activity parameters.

\section{Disc herniation}

Many studies are available in literature which examined disc herniation in asymptomatic subjects. Jensen et al. found bulging in $52 \%$ and protrusion in $27 \%$ of patients without low back pain (37). Boden et al. reported bulging and other types of hernia in $20 \%$ of patients younger than 60 years of age without low back pain (38). In Weinreb et al.'s study, the corresponding rate was 54\% among asymptomatic female patients (39). In the present study, it was $85.2 \%$ (DC: $31.1 \%$ ). Bulging was identified in $67 \%$ (DC $21.7 \%$ ) and protrusion in \%35.2 (DC 9.4\%) of our patients. Distribution of disc herniation by disc level was as follows: 4.5\% for L1-L2, $15.9 \%$ for L2-L3 disc, $22.7 \%$ for L3-L4 disc, $52.3 \%$ for L4-L5 disc and $59 . \%$ for L5-S1 disc. In a study with 200 healthy volunteers, the corresponding rates were $0.5 \%, 3.5 \%, 6.5 \%, 25 \%$ and $35 \%$ respectively (40). Consistent with other studies, disc herniation most commonly affected L4-5 and L5-S1 disc levels in the current study $(34,41)$. We did not identify a study that focused on disc herniation in AS patients. In the current study, we found an increased prevalence of disc herniation and specifically bulging in AS patients. We consider that additional disc pathologies such as Modic changes might aggravate low back pain in AS. Similarly, Albert et al. stated that disc herniation commonly occurs 
together with Modic changes and suggested that such coexistence might be closely associated with low back pain (30).

In the current study, a positive correlation was found between L1-L2 disc herniation and BASDAI and between L2-L3 disc herniation and CRP $(\mathrm{p}<0.05)$. As with Modic changes, the association between disc herniation and parameters of disease activity was significant at upper lumbar levels. Thus, examination of upper vertebral segments would provide further insight while exploring an association between disc herniation and disease activity parameters.

\section{Pfirrmann disc degeneration}

There are few studies in literature that assessed Pfirrmann disc degeneration. Frequency of disc degeneration varies across these studies. Pfirrmann et al. evaluated 300 intervertebral discs in order to perform magnetic resonance classification of intervertebral disc degeneration. In that study, grade 1 Pfirrman degeneration was found in $4.6 \%$, grade 2 in $27.3 \%$, grade 3 in $24 \%$, grade 4 in $22.6 \%$ and grade 5 in $21.3 \%$ of the discs (22). Corresponding rates were $57.7 \%, 25.5 \%, 12.7 \%, 4.1 \%$ and $0 \%$ respectively in our study. Takatalo et al. found grade 3-5 disc degeneration in $13.4 \%$ of the discs in young patients with mechanical low back pain (34). We did not identify a study that specifically explored Pfirrmann disc degeneration in AS. We believe that further studies are needed to have a clear understanding of the link between AS and Pfirrmann disc degeneration.

\section{CONCLUSION}

In the present study, we observed a high prevalence of Modic type 2 changes and bulging herniation in AS patients. We think that this might contribute to low back pain observed in 
AS. Also, Modic changes and disc herniation in upper lumbar levels were positively correlated with parameters of disease activity. Thus, studies involving thoracic spine would be of value to assess the association of degenerative disc disease with disease activity parameters. In conclusion, the present study might provide some insight for degenerative disc disease in AS. However, there is a need for studies involving the entire spine with a larger number of patients and a control group.

\section{LIMITATION}

The major limitation of the present study is the absence of a control group.

\section{REFERENCES}

1. Braun J, Baraliakos X, Golder W, Brandt J, Rudwaleit M, Listing J et al. D Magnetic resonance imaging examinations of the spine in patients with ankylosing spondylitis, before and after successful therapy with infliximab: evaluation of a new scoring system. Arthritis Rheum 2003; 48.4: 1126-1136.

2. Zochling J, Van Der Heijde D, Dougados M, Braun J. Current evidence for the management of ankylosing spondylitis: a systematic literature review for the ASAS/EULAR management recommendations in ankylosing spondylitis. Ann Rheum Dis 2006;65.4: 423-432.

3. Rudwaleit M, Baraliakos X, Listing J, Brandt J, Sieper J, Braun J. Magnetic resonance imaging of the spine and the sacroiliac joints in ankylosing spondylitis and undifferentiated spondyloarthritis during treatment with etanercept. Ann Rheum Dis 2005;64.9: 1305-1310.

4. Hochberg C, Silman j, Smolen S, Weinbaltt E, Weisman H. Rheumatology Arasil T(ed) Ankylosing Spondylitis 4th edn, Ankara Turkey, 2011:1099-1197. 
5. Manaster BJ, Roberts C, Petersilge A, Moore S, Hanrahan J, Crim J. Diagnostik İmaging, Arkun R(ed) Arthritis: Ankylosing spondylitis, Ankara Turkey, 2014: 8287.

6. Teraguchi M, Yoshimura N, Hashizume $\mathrm{H}$ et al. Prevalence and distribution of intervertebral disc degeneration over the entire spine in a population-based cohort: the Wakayama Spine Study. Osteoarthritis Cartilage 2014;22.1: 104-110.

7. Cawley MI, Chalmers TM, Kellgren JH, Ball J. Destructive lesions of vertebral bodies in ankylosing spondylitis. Ann Rheum Dis 1972 ;31.5: 345 .

8. Lentle BC, Russell AS, Percy JS, Jackson FI. Scintigraphic findings in ankylosing spondylitis. J Nucl Med:official publication, Society of Nuclear Medicine 1977;18.6: 524-528.

9. Agarwal AK, Reidbord HE, Kraus DR, Eisenbeis Jr CH. Variable histopathology of discovertebral lesion (spondylodiscitis) of ankylosing spondylitis. Clin Exp Rheumatol 1989;8.1: 67-69.

10. Kabasakal Y, Garrett SL, Calin A. The Epidemılogy Of Spondylodiscttis In Ankylosing Spondylitıs-A Controlled Study. Rheumatology 1996;35.7: 660-663.

11. Rasker JJ, Prevo RL, Lanting PJH Spondylodiscitis in Ankylosing Spondylitis, Inflammation or Trauma? Scand J Rheumatol 1996;25.1: 52-57.

12. Langlois S, Cedoz JP, Lohse A, Toussirot E, Wendling D. Aseptic discitis in patients with ankylosing spondylitis: a retrospective study of 14 cases. Joint Bone Spine 2005;72.3: 248-253.

13. Bron JL, De Vries MK, Snieders MN, Van Der Horst-Bruinsma IE, Van Royen BJ. Discovertebral (Andersson) lesions of the spine in ankylosing spondylitis revisited. Clin Rheumatol 2009;28.8: 883-892. 
14. Nguyen C, Bendeddouche I, Sanchez K et al. Assessment of ankylosing spondylitis criteria in patients with chronic low back pain and vertebral endplate Modic I signal changes. J Rheumatol 2010;37.11: 2334-2339.

15. Zinnuroğlu M, Kaya E. Modic changes and spondylodiscitis at multiple levels of the thoracolumbar spine in a patient with ankylosing spondylitis. Journal of back and musculoskeletal rehabilitation 2010;23.2: 97-100.

16. Arnbak B, Jensen TS, Manniche C, Zejden A, Egund N, Jurik AG. Spondyloarthritisrelated and degenerative MRI changes in the axial skeleton-an inter-and intra-observer agreement study. BMC musculoskeletal disorders 2013;14.1: 274.

17. Linden SVD, Valkenburg HA, Cats A. Evaluation of diagnostic criteria for ankylosing spondylitis. Arthritis Rheum 1984;27.4: 361-368.

18. Rudwaleit M, Landewe R, Van Der Heijde D et al. The development of Assessment of SpondyloArthritis international Society classification criteria for axial spondyloarthritis (part I): classification of paper patients by expert opinion including uncertainty appraisal. Ann Rheum Dis 2009;68.6: 770-776.

19. Modic MT, Steinberg PM, Ross JS, Masaryk TJ, Carter JR. Degenerative disc disease: assessment of changes in vertebral body marrow with MR imaging. Radiology 1988; 166.1: 193-199.

20. Rahme R, Moussa R. The modic vertebral endplate and marrow changes: pathologic significance and relation to low back pain and segmental instability of the lumbar spine. American Journal of Neuroradiology, 2008; 29.5: 838-842.

21. Fardon DF, Milette PC. Nomenclature and classification of lumbar disc pathology: recommendations of the combined task forces of the North American Spine Society, American Society of Spine Radiology, and American Society of Neuroradiology. Spine 2001; 26.5: E93-E113. 
22. Pfirrmann CW, Metzdorf A, Zanetti M, Hodler J, Boos N. Magnetic resonance classification of lumbar intervertebral disc degeneration. Spine 2001;26.17: 18731878.

23. Weishaupt D, Zanetti M, Hodler J, Boos N. MR imaging of the lumbar spine: prevalence of intervertebral disc extrusion and sequestration, nerve root compression, end plate abnormalities, and osteoarthritis of the facet joints in asymptomatic volunteers. Radiology 1998; 209.3: 661-666.

24. Chung CB, Berg BCV, Tavernier T, Cotten A, Laredo JD, Vallee C et al. End plate marrow changes in the asymptomatic lumbosacral spine: frequency, distribution and correlation with age and degenerative changes. Skeletal Radiol 2004;33.7: 399-404.

25. Jensen TS, Bendix T, Sorensen JS, Manniche C, Korsholm L, Kjaer P. Characteristics and natural course of vertebral endplate signal (Modic) changes in the Danish general population. BMC musculoskeletal disorders 2009;10.1: 81.

26. Toyone T, Takahashi K, Kitahara H, Yamagata M, Murakami M, Moriya H Vertebral bone-marrow changes in degenerative lumbar disc disease. An MRI study of 74 patients with low back pain. J Bone Joint Surg Br 1994;76.5: 757-764.

27. Kuisma M, Karppinen J, Niinimäki J, Kurunlahti M, Haapea M, Vanharanta H et al. A three-year follow-up of lumbar spine endplate (Modic) changes. Spine 2006;31.15: 1714-1718.

28. Kjaer P, Korsholm L, Bendix T, Sorensen JS, Leboeuf-Yde C. Modic changes and their associations with clinical findings. European Spine Journal 2006:15.9: 13121319.

29. Jarvik JG, Hollingworth W, Heagerty PJ, Haynor DR, Boyko EJ, Deyo RA. Threeyear incidence of low back pain in an initially asymptomatic cohort: clinical and imaging risk factors. Spine 2005;30.13: 1541-1548. 
30. Albert HB. Manniche C Modic changes following lumbar disc herniation. Eur Spine J 2007;16.7: 977-982.

31. Kjaer P, Leboeuf-Yde C, Korsholm L, Sorensen JS, Bendix T. Magnetic resonance imaging and low back pain in adults: a diagnostic imaging study of 40 -year-old men and women. Spine 2005;30.10: 1173-1180.

32. Schenk P, Läubli T, Hodler J, Klipstein A. Magnetic resonance imaging of the lumbar spine: findings in female subjects from administrative and nursing professions. Spine 2006;31.23: 2701-2706.

33. Jensen TS, Karppinen J, Sorensen JS, Niinimäki J, Leboeuf-Yde C. Vertebral endplate signal changes (Modic change): a systematic literature review of prevalence and association with non-specific low back pain. Eur Spine 2008;17.11: 1407-1422.

34. Takatalo J, Karppinen J, Niinimäki J, Taimela S, Näyhä S, Järvelin $M$ et al. Prevalence of degenerative imaging findings in lumbar magnetic resonance imaging among young adults. Spine 2009;34.16: 1716-1721.

35. Karchevsky M, Schweitzer ME, Carrino JA, Zoga A, Montgomery D, Parker L. Reactive endplate marrow changes: a systematic morphologic and epidemiologic evaluation. Skeletal Radiol 2005;34.3: 125-129.

36. Kuisma M, Karppinen J, Niinimäki J et al. Modic changes in endplates of lumbar vertebral bodies: prevalence and association with low back and sciatic pain among middle-aged male workers. Spine 2007;32.10: 1116-1122.

37. Jensen MC, Brant-Zawadzki MN, Obuchowski N, Modic MT, Malkasian D, Ross JS. Magnetic resonance imaging of the lumbar spine in people without back pain. $\mathrm{N}$ Engl J Med 1994;331.2: 69-73. 
38. Boden SD, Davis DO, Dina TS, Patronas NJ, Wiesel SW. Abnormal magneticresonance scans of the lumbar spine in asymptomatic subjects. A prospective investigation. J Bone Joint Surg Am 1990;72.3: 403-408.

39. Weinreb JC, Wolbarsht LB, Cohen JM, Brown CE, Maravilla KR. Prevalence of lumbosacral intervertebral disc abnormalities on MR images in pregnant and asymptomatic nonpregnant women. Radiology 1989;170.1: 125-128.

40. Kanayama M, Togawa D, Takahashi C, Terai T, Hashimoto T. Cross-sectional magnetic resonance imaging study of lumbar disc degeneration in 200 healthy individuals: Clinical article. J Neurosurg 2009;11.4: 501-507.

41. Ong A, Anderson J, Roche J. A pilot study of the prevalence of lumbar disc degeneration in elite athletes with lower back pain at the Sydney 2000 Olympic Games. Br J Sports Med 2003;37.3: 263-266. 
Table 1: Patient characteristics. Values are expressed as $\mathrm{n}(\%)$, mean $\pm \mathrm{SD}$ or median (min$\max )$

\begin{tabular}{ll}
\hline VARIABLE & STATISTIC \\
\hline $\begin{array}{l}\text { Age (years) } \\
\text { Gender }\end{array}$ & $40.34 \pm 9.67$ \\
Male & $50(56.8)$ \\
Female & $38(43.2)$ \\
Sacroiliac Screening & \\
MRI sacroiliitis & $66(75.0)$ \\
Radiographic grade III sacroiliitis & $14(15.9)$ \\
Radiographic grade IV sacroiliitis & $8(9.1)$ \\
& \\
Laboratory values & \\
ESR & $10.25(2.00-58.00)$ \\
CRP & $4.80(3.30-46.40)$ \\
BASDAI & $5.23 \pm 2.12$ \\
\hline
\end{tabular}


Table 2: Summary of the prevalence of disc bulging, protrusion, extrusion, disc degeneration levels and Modic changes in the MRI studies. Values are expressed as n (\%)

\begin{tabular}{lllllll}
\hline VARIABLE & \multicolumn{7}{c}{ DISC DISTANCE } \\
\hline & L1-L2 & L2-L3 & L3-L4 & L4-L5 & L5-S1 & Total \\
\hline MODIC & & & & & \\
Normal & $82(93.2)$ & $83(94.3)$ & $80(90.9)$ & $73(83.0)$ & $65(73.9)$ & $383(87)$ \\
Modic-I & $2(2.3)$ & $1(1.1)$ & $2(2.3)$ & $3(3.4)$ & $8(9.1)$ & $16(3.6)$ \\
Modic-II & $4(4.5)$ & $4(4.5)$ & $5(5.7)$ & $12(13.6)$ & $14(15.9)$ & $39(8.9)$ \\
Modic-III & $0(0.0)$ & $0(0.0)$ & $1(1.1)$ & $0(0.0)$ & $1(1.1)$ & $2(0.5)$ \\
PFIRMANN & & & & & & \\
& & & & & & \\
Pfirmann -I & $70(79.5)$ & $64(72.7)$ & $51(58.0)$ & $34(38.6)$ & $35(39.8)$ & $254(57.7)$ \\
Pfirmann -II & $9(10.2)$ & $15(17.0)$ & $26(29.5)$ & $36(40.9)$ & $26(29.5)$ & $112(25.5)$ \\
Pfirmann -III & $3(3.4)$ & $8(9.1)$ & $8(9.1)$ & $16(18.2)$ & $21(23.9)$ & $56(12.7)$ \\
Pfirmann -IV & $6(6.8)$ & $1(1.1)$ & $3(3.4)$ & $2(2.3)$ & $6(6.8)$ & $18(4.1)$ \\
DISC & & & & & & \\
PROLAPSU & & & & & & \\
S & & & & & \\
Normal & $84(95.8)$ & $74(84.1)$ & $68(77.3)$ & $41(46.6)$ & $36(40.9)$ & $303(68.9)$ \\
Bulging & $4(4.5)$ & $12(13.6)$ & $17(19.3)$ & $35(39.8)$ & $27(30.7)$ & $95(21.6)$ \\
Protrusion & $0(0.0)$ & $1(1.1)$ & $3(3.4)$ & $12(13.6)$ & $25(28.4)$ & $41(9.3)$ \\
Extrusion & $0(0.0)$ & $1(1.1)$ & $0(0.0)$ & $0(0.0)$ & $0(0.0)$ & $1(0.2)$ \\
\hline
\end{tabular}

Table 3: Spearman correlation coefficients among Modic changes, Pfirrmann scale, disc herniation and ESR, CRP, BASDAI

\begin{tabular}{lccccc}
\hline \multicolumn{1}{c}{ VARIABLE } & \multicolumn{5}{c}{ DISC DISTANCE } \\
\hline & L1-L2 & L2-L3 & L3-L4 & L4-L5 & L5-S1 \\
\hline MODIC & & & & & \\
ESR & -0.171 & -0.170 & -0.074 & -0.002 & 0.086 \\
CRP & 0.034 & -0.086 & 0.010 & 0.149 & 0.155 \\
BASDAI & 0.025 & 0.131 & 0.141 & 0.064 & 0.100 \\
PFIRMANN & & & & & \\
ESR & -0.191 & -0.123 & -0.119 & -0.112 & -0.010 \\
CRP & -0.057 & -0.099 & -0.052 & 0.063 & 0.030 \\
BASDAI & 0.117 & 0.219 & -0.025 & 0.343 & 0.072 \\
& & & & & \\
DISC & & & & & \\
PROLAPSUS & -0.262 & 0.082 & -0.134 & -0.007 & -0.018 \\
ESR & -0.129 & 0.023 & -0.001 & 0.058 & -0.128 \\
CRP & 0.022 & 0.203 & 0.120 & 0.264 & 0.105 \\
BASDAI & & & & & \\
\hline
\end{tabular}




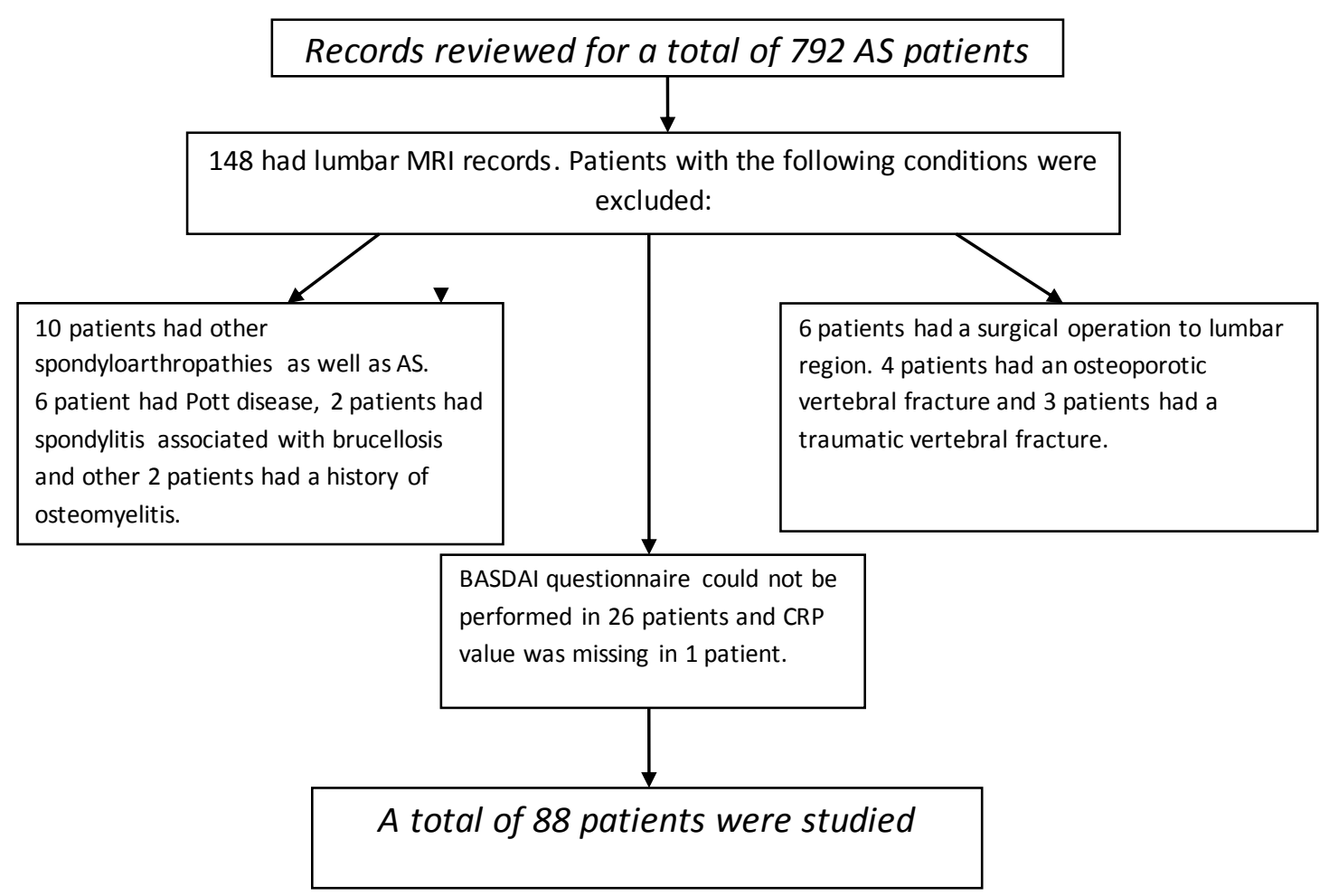

Fig 1: Flowchart diagram

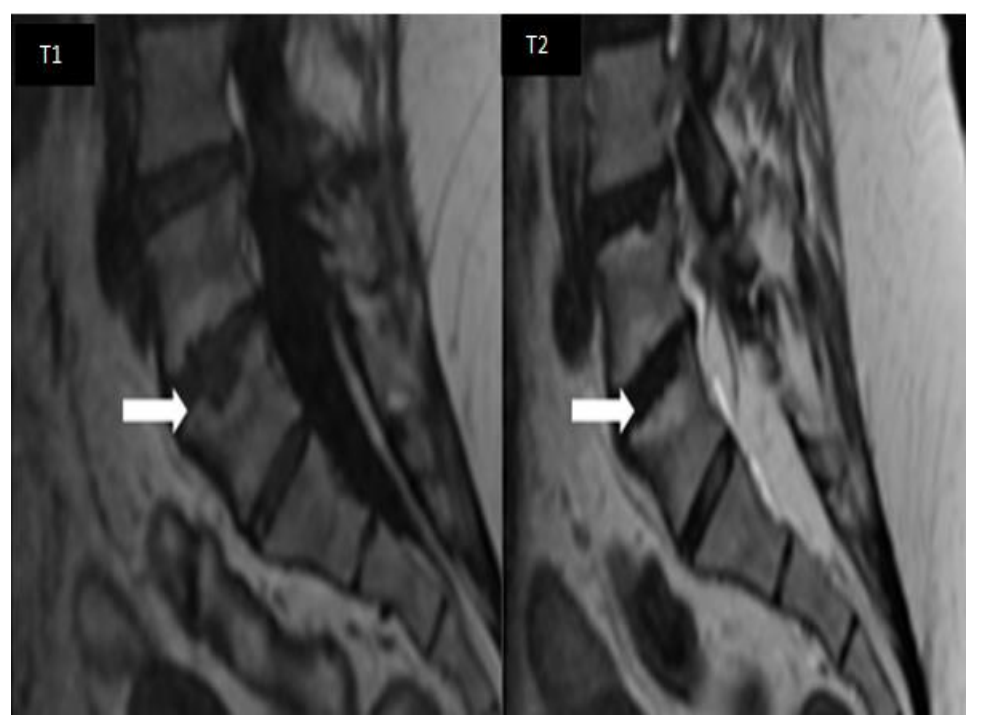

Fig 2: Modic type 1 change observed in sagittal T1 and T2 sections. 


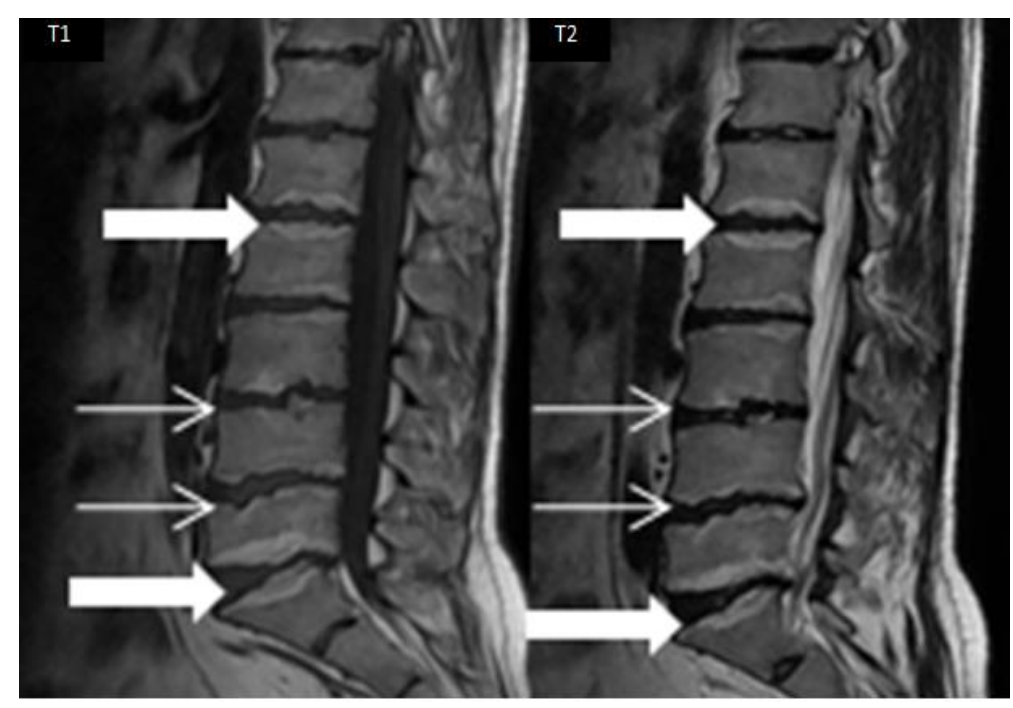

Fig 3: Pfirrmann grade 4 degeneration (thin arrow) and Modic type 2 change (thick arrow) seen in sagittal $\mathrm{T} 1$ and $\mathrm{T} 2$ sequences. 